\title{
Unconventional Doctoring: A Medical Student's Reflections on Total Suffering
}

\author{
Sophia Paraschos, BA
}

$\mathbf{P}$ ALLIATIVE CARE DOCTORS are known for their sometimes unconventional methods of alleviating suffering. In addition to home visits, they are comfortable with interventions like intrathecal pumps and sub-q Lidocaine for pain control, low-dose Haldol for intractable hiccups, and chaplain consults when physical pain is not the only source of suffering. Sometimes the team can subdue a patient's suffering by managing physical symptoms-pain, nausea, fatigue-but rarely was this unilateral approach enough. I spent a day with a chaplain and began to understand that even the most empathetic physician's healing can only extend so far, that there is a suffering patients can only address in the context of their faith. I spent a day with a hospice music therapist and sang the "Battle Hymn of the Republic" with an 87-year-old former physician, dying of pulmonary fibrosis, whose profound shortness of breath seemed to wholly subside when he belted out those familiar lyrics.

Someday I will be able to palliate pain, nausea, or shortness of breath with a prescription pad, but as a medical student on palliative care, my role was not to prescribe. I could listen. I could sing along. I could be present in silence (and for someone who loves talking as much as I do, this was somewhat of a challenge). Time spent listening to patients-one of the most important and meaningful opportunities for a medical student-is always well spent. Occasionally patients will volunteer information about something they love or they miss while in the hospital, and often it is something that is easy to provide. For one patient it was a popsicle. I knew where to find those from my time on the pediatrics floor. I could quickly run there to get him one; I think it made his day, but I know it made mine. These moments are often the most memorable and rewarding moments in a medical student's life.

At $6 \mathrm{pm}$ on my last day of palliative care we were consulted on a Liberian man in terrible pain from metastatic prostate cancer. His prognosis was unclear, but he was extraodinarily appreciative of our attention to his pain. When he mentioned he was from Liberia it occurred to me that Liberian President and Nobel Peace Prize Laureate Ellen Johnson Sirleaf would be just outside this patient's window giving the commencement speech to the medical school's graduating class that weekend....and that I had an extra ticket in my white coat pocket for the event. Once again, the patient broke into a huge smile. "My country's president!" he said, "And I will get to see her!" Being somewhat familiar with the recent history of Liberia and the horrific civil war there, I knew that President Sirleaf was more than just a political figurehead to anyone who had lived through the civil war and witnessed the hardwon rebuilding of the country. For her people, she symbolized peace, stability, and hope.

But on graduation day the patient was nowhere to be found in the tent. I found him in his room on the seventh floor, and he explained to me that though we had included a signed order in the chart for permission to be wheeled downstairs to the event on the lawn, the nurse did not feel comfortable letting him go without professional supervision, and the floor was too busy for anyone to take him down. I promised her and the resident on call that I would stay with him throughout the speech and wheel him back up afterward. They finally agreed, and we made it to the tent just in time for her introduction and honorary degree presentation. We sat there together, taking pictures and listening to her speech about struggle, healing, and great perseverance. We participated in the standing ovation, and then I returned the patient to the floor as promised. As I hugged him goodbye he said the words a medical student lives to hear: "Thank you. God bless you. I will never forget you."

Address correspondence to: Sophia Paraschos, BA

University of Massachusetts Medical School 55 Lake Avenue North Worcester, MA 01655

E-mail: sophia.paraschos@umassmed.edu

University of Massachusetts Medical School, Worcester, Massachusetts. 